\title{
Effective assimilation of technological innovation in an organization characterized as a Complex Adaptive System (CAS)
}

\author{
Alon E. Hasgall \\ alon_h@mla.ac.il | The Center for Academic Studies, O Yehuda, Israel; 34, Tzoran. Pob. 5203, \\ Shoham, 6085000. Israel \\ Niv Ahituv \\ ahituv@post.tau.ac.il | Tel Aviv University, Israel \\ Nily Naveh \\ nilinaveh@gmail.com | VP Pedagogy and Technology. National Educational Network. Israel
}

\begin{abstract}
Most organizations seek for innovative solutions to address external changes and competition. However, each organization is required to launch rapid and effective processes in order to assimilate the technological innovation. The purpose of this study was to understand whether an organization characterized as CAS (Complex Adaptive System) can affect the process of assimilating technological innovation. CAS organizations are naturally decentralized, and contain sub-systems named "fractals" that allow an immediate reaction to change in the environment, while simultaneously informing and updating all other sub-systems. A sample of 300 employees from 15 organizations of different sectors responded to an online questionnaire. Pearson and regression analyses were used to examine the relationships between the functioning of the workers as fractals in CAS organizations and their attitude toward the process of assimilation of technological innovation. The findings indicate that workers functioning as knowledge-worker were able to adhere to personal benefits together with organizational goals. They had sensitivity to changes in the environment, integration of the information required for the process, and the ability to socialize among themselves. These abilities have significantly influenced the development of positive attitudes towards the process of assimilation of technological innovation, a better understanding of the technology and its advantages to them, which make them ready to be involved in the process. The practical contribution of this study is the ability to best portray the characteristics of an optimal work environment in an organization that wishes to encourage technological innovation, to undergo assimilation processes, and to manage the dissemination of relevant knowledge for organizational use. Such an organization is required to provide its employees with a certain degree of operational autonomy, enabling them to interweave personal interests and organizational goals, and to be involved and to influence the processes of assimilating technological innovation in the organization.
\end{abstract}

Keywords. Innovation; Technology Assimilation; Complex Adaptive Systems; Fractals.

Cite paper as: Hasgall, E.A., Ahituv, N., Naveh, N., (2019). Effective assimilation of technological innovation in an organization characterized as a Complex Adaptive System (CAS), Journal of Innovation Management, www.open-jim.org, 7(2), 38-58. 


\section{Background and literature review}

The 21st century market is typified by continuous changes in consumer habits and preferences, by innovative technology that is rapidly reaching commercial maturity, and by new competitors that manage to overcome barriers to enter into the market by using technological innovation (Jackson, 2010) that can disrupt the competitiveness of the organization (Christensen, Bartman, and Van Bever, 2016). The latest development of different contemporary technologies affects all areas of work in the organization. Both on the work processes in the organizations and on the method of management, administration, and customer service. The organizations now a days, employ means such as internal information systems, global communications systems, big data sources, social networks, and mobile applications. In recent years, artificial intelligence has begun upgrade the automation and use of robotics. These technological innovations enable to upgrade the quality of the organization's products and services, to improve performance, to reduce costs, and to improve employee working conditions while maintaining competitiveness (Zhu, Kenneth and Xu, 2006). Enterprise management should carefully examine technological changes and innovations in their relevant environment in an attempt to identify the most appropriate innovation. As the rate of technological innovation increases dramatically, organizations need a high level of adaptation and tolerance to changes: to be more up-to-date, to identify innovative technologies that will advance the organization's competitiveness, and to employ processes to implement this innovation in products and technologies (Potter and McGittigan, 2013).

\subsection{What is innovation?}

Organizational innovation is defined as the development of a new product or service (Jackson, 2011), or even a major modification of an existing product or service. This may include the expansion of new products, services and markets, production methods, or a value-added management approach to the organization (Crossan and Apaydin, 2010, Lundvall, 2010). Innovation is a result of an "out of the box" thinking, and its outcomes generate a breakthrough phenomenon that represents a potential improved product or service aimed at upgrading the value of the product or service to the customer (Schumpeter, 1991). When talking about innovation, it is commonly used in terms of creativity and entrepreneurship to create a better profitability while maintaining a high level of customer satisfaction. The process of innovation involves creating an alternative idea to an existing situation that in a linear process transforms the idea from a raw state to a unique conceptual framework, and then to the practical development of a business model to maintain profitability over time (Garud, Tuertcher and Van de Ven, 2013). Innovation also includes higher-quality versions of existing products, and the assimilation of products and services in new markets, new production or distribution methods, new sources of production for existing products or even new forms of economic organization in the organization (Denning and Dunham, 2010). Innovation can be observed on two levels: incremental (evolutionary) and radical. "Revolutionary technological innovation also includes" disruptive "innovation - innovation based on a product or service that is not perceived as threatening or necessary, but at a certain point of time may change the market in a way that no one expects. If a market-leading organization ignores the emergence of a new competitive factor in the market Considered "niche", 
this could disrupt the organization's competitive ability and cause the company to collapses" (Christensen, Bartman, and Van Bever, 2016). In the 21st century, technological innovation has become a major factor in understanding the business and economic structure of the company. However, the constant need of organizations to create innovation began to cause a process of "creative destruction" - a continual process of removing old technology and the introduction of new technology, sometimes without examining the organization's ability to assimilate innovation (Potter and McGittigan, 2013). Technological innovation is now seen as the driving the wheels of business, economics and society in general. As a result, the processes of assimilating new technologies in the organization have become critical.

\subsection{Organizational innovation management}

Achieving success requires the development of complex business models and complex internal processes. It was found that the greater the degree of decentralization and accessibility to internal information, the greater the ability to cope with external complex relationships (Snihura and Tarzijan, 2018). Over the years, various models have developed for organizational innovation management. A leading one is the integrative model for management of innovation in the organization. It is implemented in three stages: initiation and adoption, increasing willingness to receive technological innovation, and integration of innovation in organizational processes. Several criteria affect the effective adoption process and the ability to integrate innovation into the organization: an orderly process of initiation, the scope of innovation embedded in the organization, the intensity of competition, the regulatory environment, and management obstacles (Freeman and Soete, 2009). It was also found that the larger the organization, the more emphasis it places on integrating a broader range of technological innovation over time (Zhu, Kraemer and $\mathrm{Xu}, 2006)$. A new study found that intensive competition in the organization's environment does add to organizational entrepreneurship, but limits the process of managing innovation assimilation, as there is a desire to rapidly promote processes and carry out long-term assimilation processes (Akgün et al, 2014). The Company's management is committed to locating the innovative products in different niches that may threaten the Company's status, while ignoring innovation that is not relevant at all. Today, there is a mess of complex analytical tools that allow the organization to focus on risky products. However, examples of organizations that have lost their stability [such as Digital] or organizations that maintain their market standing despite the ongoing controversy with disruptive new niches [such as Apple] need to identify and track innovations, an ongoing warning process that enables decision making within a short time. This process cannot be done only by senior management, or using advanced analytical tools, but with the participation of most of the employees (Christensen, Bartman, and Van Bever, 2016). Thus, effective management of innovation is a process that adapts innovation to the business model of the organization or changes the business model to more effective implementation of technological innovation, while adapting the organization's work processes, product quality, and profit level (Potter and McGittigan, 2013). Innovation management in the organization must be done quickly and accurately in all processes of production, marketing, and quality, in accordance with the relevant target audiences (Christensen, Bartman, and Van Bever, 2016) 


\subsection{Assimilating technological innovation}

"Assimilation" is a concept that expresses a process in which an organism adapts resources that it absorbs from the natural environment it needs for its existence. The resources vary according to the changes in the environment and therefore, the assimilation process requires constant adaptation of the organism to its environment. A human also performs such an assimilation process, whether alone (e.g., in a boat at sea) or is in a group or an organization. In an environment where there are many changes, the resources required for the organization are also changing, so the organization needs to constantly adapt and change while acquiring varying resources from the environment (Potter and McGittigan, 2013). Innovation, by definition, is a process of change and development of new technologies. A survey of 144 companies conducted in Spain shows a direct link between the rise in innovation in the organization and the assimilation of new technologies. It turns out that technology contributes to streamlining work processes in improving the work environment (Camisón and Villar-López, 2014). Therefore, an organization in the 21st century, which is under a very rapid development of technological innovation, needs to continuously adapt to the rapidly changing environment (Stacey, Griffin and Shaw, 2000). The changes required in the organization relate to the organizational structure, employee roles, business model, work methods, organizational culture, social atmosphere, and management method (Garud, Tuertcher and Van de Ven, 2013). If the process is carried out effectively, the expected results might improve product quality, customer satisfaction, cost reduction, and organizational profit (Anjariny, Zeki and Hussin, 2012).

However, any process of permanent status change is likely to change the status quo. In a state of assimilation and adoption of technological innovation, the employees value the effort required from them in order to achieve the organizational goals while maintaining their status and working conditions. This assessment determines the extent of their consent or opposition to the process. This process is called the "information processing model". It can lead to negative emotions and resistance by developing a sense of self-threat and lack of usefulness in the worker's work, due to the fear of heavy workload, reduction of status, and changes in the traditional way of performing tasks (Bessen, Ford and Meurer, 2011). The traditional approach to assimilation emphasizes the top-down direction as well as the tight control of changes, allowing managers to cope better with the difficulty of losing control (Anjariny, Zeki and Hussin, 2012) The basic assumption is that procedures facilitate the process of assimilation (Potter and McGittigan, 2013.) This approach does not take into account the employee's ability to perform "rational thinking" and reach agreement. The "consent" factor can influence the reduction of resistance, acceptance of the change, involvement in the process of assimilation of technological innovation, and gaining a faster and more efficient improvement of processes after assimilation. The "consent" factor of employees is expressed, among other things, in the significant correlations found in research, between the employee's ability to cope successfully with organizational changes, adapting work processes and resources to his needs, and the variety of options that the worker receives in the work environment at the organization (Andriani and Cattani, 2016). Therefore, it is important for the managers of the organization to create a process of consent that will lead to positive attitudes of employees towards the newly embedded technology. The acceptance model explains the need for a transparent and agreed process between employees in applying innovation (Armstrong and Sambamurthy, 1999). Consent requires not only sharing of the idea, but also a well-managed 
assimilation process. Intermediate steps and milestones should be defined according to the traits that characterize the organization. There is a need for a process of training and building the innovative solution in the work environment, even if it changes the lifestyle of the employee or the manager (Arciénaga Morales, et al, 2018).

Planning a process of agreement before the implementation begins is the main challenge. Such process can hone the employee's perception and convince that this adoption can improve the working conditions, facilitate the work, and improve his/her position in the organization and the organization's status in the competitive environment (Arciénaga Morales et al, 2018). Such a planned process requires prioritization of organizational activity, employment planning, and budget assessment (Bessen, Ford and Meurer, 2011). The process takes at least five stages that combine the organization's goals with the employee's interests in order to create the employee's sympathy, consent, and involvement: Awareness - The employee becomes aware of innovation and is exposed to collecting information related to it. Persuasion - the employee is attracted to the innovation and is actively seeking information about it. Decision - The employee assesses the innovation and form an attitude towards it. The attitude can be sympathetic or antagonist. Permanent use - the employee decides to adopt the innovation and use it on a regular basis. Confirmation - the employee receives approvals or reinforcement from the environment and the management regarding the adoption of the innovation (Oliveira and Martins, 2011).

In this study, we try to understand what can affect the employee's ability to successfully integrate the organization's goal of succeeding in adopting a new technology, and develop a sympathetic perception of the changes, implying awareness and agreement that the new technology can improve the working conditions and the status in the organization.

\subsection{The organization as a Complex Adaptive System (CAS)}

A Complex Adaptive System [CAS] contains a collection of autonomous subsystems that have a common affinity, interdependence, and processes that work for a common goal. Such subsystem is named "fractal" (Stacey, Griffin and Shaw, 2000). The complex model of adaptive systems (CAS) is found in many structures in nature such as leaf arteries, snowflake structure, ants' convoy, and a swarm of sardines. The decentralized structure allows each fractal to react immediately to changes in its environment while simultaneously updating other fractals to the environmental changes it recognizes. Fractals in CAS are independent employees who have access to the resources they need, but at the same time interact with other fractals and continuously share information with them allowing for quick sensitivity to changes in the environment and faster response (Holland, 2006, Zimmerman and Hrust, 1993). An analysis of the fractal function in CAS shows that the effectiveness of the complex system is based on two opposing processes. An autonomous ability of each fractal in the execution of its task, simultaneously with performing constant integration of information and resources with all other fractals. Thus, each unit can benefit from the knowledge and resources of other fractals and regularly share knowledge and resources with them. Because of this structure, each fractal can respond directly and immediately to changes occurring in the environment while simultaneously updating the rest of the system about the changes it detects. (Stacey, Griffin and Shaw, 2000). For these reasons, the CAS 
model provides a high level of survival in nature and is therefore considered a successful model replicated in many structures in nature.

It was two decades ago that the relationship between CAS systems in nature and human behavior in modern organizations was identified to portray a complex and changing environment (Roos and Oliver, 1997). Systems characterized by CAS enable intelligent coping with changing processes. It was found that these systems also exist in the human and social level. But since a human environment is characterized by behaviors that are not always repetitive, and they are based on emotion, power, and control, the results cannot be expected to repeat themselves as in natural systems. Human solutions in CAS will vary according to the person's needs, not just the system requirements (Törnberg, 2014). Subsequently, there was a positive correlation between the degree to which businesses and government organizations can be characterized as CAS, and the ability of employees in these organizations to cope with environmental changes successfully. The more the organization is characterized by CAS, the greater the ability of each employee to reach innovative solutions and help the organization coping with a dynamic environment more effectively (Shoham and Hasgall, 2005).

Workers in organizations that function as a CAS show four distinct behavioral characteristics, which allow them to function as autonomous fractals and to constantly update and be updated of organizational activities (Hasgal and Ahituv, 2017):

Operational autonomy: The employee is considered an expert in his profession. The employee can demonstrate his abilities, expertise, and interests. The employee can make decisions autonomously. Employee works respectively for immediate solutions, as a sub-system (= fractal) under the backing of the organization.

Environmental sensitivity: The worker is granted the ability to sense the external environment and to respond to changes in this environment in a consistent and methodological manner. This capability allows the worker to adjust the relevant solutions to the needs of the managers and to the demands of the customers.

Integration of information: The worker share knowledge and can use methods and organizational systems to integrate various types of information that are found in shared databases and in the databases of other workers.

Social networking: The worker can manage his or her social resources in a distributed and synchronized manner to share information, find innovative solutions, and self-develop.

The findings of the study showed that an organization that enables employees to function as fractals increase the organizational ability to cope with environment changes. Fractals behavior create The Knowledge worker who operate autonomously, communicate, update and share knowledge with other employees.

\subsection{Assimilating technological innovation in CAS Organizations}

Successful implementation of technological innovation is critical to the organization's ability to adapt to its environment and turn itself into a competitive and successful organization. Howe- 
ver, this process may be long and complex, and may be difficult for workers and arouse objections.

Various studies have shown the relationship between the CAS organization and the involvement of organizations in promoting its goals and in developing innovation. A Study that examined how organizations defined as CAS adjust to a dynamic and changing environment, found that in those organizations, workers were given the possibility of coordinating activities among them, through social interactions and work involvement. It was found that employees, initiated innovation in a new product development processes (NPD), on demand (Akgün et al, 2014). Another research found that knowledge workers in an organization with CAS characteristics knew how to combine the organization's goals with their personal benefit, share knowledge, and be part of a social network that supports the organization (Shoham and Hasgall, 2005). Thus, it can be assumed that in an organization with CAS characteristics and employees functioning as fractals, more positive approaches to desirable change processes will emerge (Hasgall, 2015). These positive approaches have a high potential for positively influencing the process of assimilating technological innovation in the organization.

The next part of this article presents some empirical findings related to that assertion.

\section{The empirical study}

This section presents the research question, variables, the hypotheses, and the results of the empirical study.

\subsection{Research question:}

Considering all above, our research question is: Can an organization with CAS characteristics [independent variables] influence the development of positive attitudes and involvement of employees in the process of assimilation of technological innovation in the organization over time?

\subsection{Research variables}

\section{Dependent variable:}

"The employee's attitude towards innovation in the organization" (Oreg, 2003). According to the "Acceptance Model", the worker's attitudes towards the process of assimilating the innovation will predict the extent of his investment and the degree of his willingness to assimilate organizational innovation in his work environment (Armstrong and Sambamurthy, 1999). 
The characteristics of the worker's attitudes are based on the following dimensions (Oreg, 2003):

A. The employee's perception of the impact of the new technology on organizational processes. This dimension was assessed by four questions on a scale from "1" (the perception that the new technological technology does not affect organizational processes) to 5 (corresponds to the perception that the new technology greatly influences organizational processes). The average response to the four questions was calculated and used as an indicator of the "degree of impact" dimension.

B. The extent to which the employee is personally involved in the process of integrating the innovative technology in the organization. This dimension was assessed using four questions, which respondents answered on a scale from "1" (corresponding to minimal involvement in the process) to 5 (corresponding to high involvement in the process). The average response to the four questions was calculated and used as an indicator of the personal involvement dimension.

C. The type of emotional response of the employee to the integration of new technologies in the organization. This dimension was assessed using five questions, which respondents answered on a scale from 1 (relating to stress and anxiety with respect to the new technology) to 5 (in accordance with the calmness of the new technology). The average response to the five questions was calculated and used as an indicator of the "emotional response" dimension, with higher values ??indicating a less anxious attitude toward modern technology.

\section{Independent variables:}

An organization with the characteristics of CAS is an organization in which "knowledge workers" can function as fractals, implying that they can test innovation, and find its advantages more effectively, thus influence its positive attitudes (Hasgall, 2015). The characteristics of the organization as a CAS have four different dimensions:

A. Operational Autonomy - The ability to act on an immediate solution based on an autonomous decision. This variable was assessed by four questions, which respondents answered on a scale from 1 (= no benefit) to 5 (= high personal benefit). The average response to the four questions was the measure of the utility benefit of innovation per worker.

B. Environmental sensitivity - the employee's ability to identify and respond to changes in the organizational environment in a methodological and consistent manner. This variable was assessed using four questions, which respondents responded to on a scale from 1 (low awareness of environmental changes) to 5 (= high awareness of environmental changes). The average response to the four questions was the measure of the "environmental sensitivity" variable.

C. Information integration - Knowledge sharing base on the employee's ability to integrate information from various organizational sources and systems. This variable was assessed using four questions, which respondents responded to on a scale from 1 (= inability to integrate information from different sources) to 5 (= high ability to integrate information 
from different sources). The average response to the four questions was used as a measure of the "integration of information" variable.

D. Social networking - the ability to manage social resources in a distributed and synchronized manner. This variable was assessed using four questions, which respondents answered on a scale from 1 (= organizational isolation) to 5 (= high level of continuous social networking). The average response to the four questions was used as a measure of the variable "Networking".

\subsection{The method of analysis}

For each variable, descriptive measures [mean and standard deviation] were specified. Each hypothesis was measured using Pearson's correlation. The higher and positive correlation was found, the conclusion was that there was a strong positive correlation between the variables.

\subsection{Hypotheses}

Hypothesis 1: There is a correlation between the variable "Operational autonomy, that characterizes a knowledge worker in the organization as CAS" and the variable "positive attitudes of an employee towards the innovation embedded in the organization" [In dimensions of: enthusiasm, influence and involvement].

Hypothesis 2: There is a correlation between the variable "sensitivity to changes in the environment that characterizes the knowledge worker in the organization as CAS"?? [Which includes the dimensions: transparency and knowledge sharing], and the variable "??positive attitudes of an employee towards the innovation embedded in the organization" [In dimensions of: enthusiasm, influence and involvement].

Hypothesis 3: There is a correlation between the variable "?the integration of information that characterizes a knowledge worker in an organization as a CAS", and the variable ?"positive attitudes of an employee towards the innovation embedded in the organization"?? [In dimensions of: enthusiasm, influence and involvement].

Hypothesis 4: There is a correlation between the variable "social networking that characterizes a knowledge worker in an organization as a CAS" and the variable "the positive attitudes of an employee toward the innovation embedded in the organization" [In dimensions of: enthusiasm, influence and involvement].

\subsection{The sample}

Sample: 300 subjects were sampled in clusters of organizations [11 organizations] and professions [4 types].

$48.3 \%$ of the respondents were males and $51.7 \%$ were females. The distribution of the subject by profession is displayed in Figure 1. 


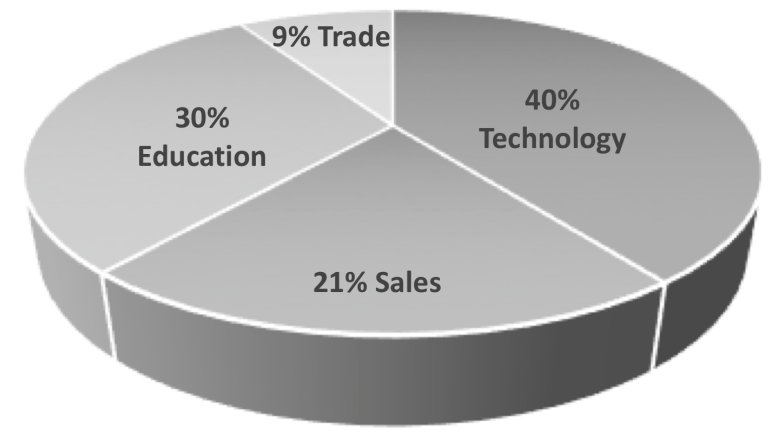

Fig. 1. Distribution of Subjects by Profession

The types of organizations from which the workers were sampled as shown in figure 2: 5 high-tech organizations (computers and technology) 46\%. 3 educational and teaching organizations 27\%, 3 trade and business organizations $27 \%$. Division of respondents by profession: Technology professionals $-40 \%$ of respondents. Sellers $-21 \%$. Teachers and instructors about $30 \%$. Merchants $-9 \%$ of respondents.

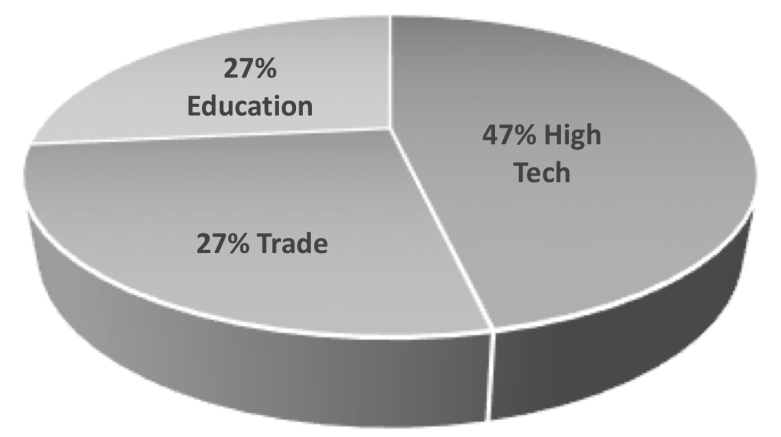

Fig. 2. Organization Type

\section{Results}

The results are presented in Table 1. Accordance with the Dimensions of the variable.

Table 1. Descriptive statistics of the dimension of dependent variable

\begin{tabular}{llcc}
\hline Dependent variable & Dimension & Mean & $\begin{array}{c}\text { Standard } \\
\text { Deviation }\end{array}$ \\
\hline \multirow{3}{*}{$\begin{array}{l}\text { Employee attitudes towards } \\
\text { innovation }\end{array}$} & Emotional response & 2.2 & 0.048 \\
\cline { 2 - 4 } & $\begin{array}{l}\text { The effect of innovation on } \\
\text { employee work }\end{array}$ & 3.7 & 0.048 \\
\cline { 2 - 4 } & Employee involvement & 3.5 & 0.045 \\
\hline
\end{tabular}


1. The dependent variable: Employee attitudes towards innovation:

- Emotional response from stress to enthusiasm, average $=2.2$ SD standard deviation $=$ 0.048. The level of enthusiasm for innovation was medium and common to most workers.

- The effect of innovation on employee work: Average $=3.7$ standard deviation $=0.048$. The degree of influence was relatively high among most workers.

- Employee involvement: average $=3.5$ standard deviation $=0.043$. The degree of desire for involvement was relatively high among most of the workers.

2. Independent variables: "Characteristics of the adaptive complex system".

- The dimensions of this variable will be specified as part of the hypothesis test.

\subsection{Hypothesis testing}

The hypotheses were examined using Pearson correlation analysis and the significant unique contribution of each dimension in each hypothesis. The results are presented in Table 2.

Table 2. Predictive indicators of the variable: Attitude toward the technological innovation [by 3 dimensions: degree of influence, personal involvement, and emotional response]

\begin{tabular}{llclc}
\hline $\mathbf{V 1}$ & $\mathbf{V 2}$ & $\mathbf{R}^{\mathbf{2}}$ & $\begin{array}{l}\text { Significant } \\
\text { unique } \\
\text { contribution }\end{array}$ & $\begin{array}{c}\text { Beta } \\
\text { (Regression) }\end{array}$ \\
\hline $\begin{array}{l}\text { CAS: } \\
\text { Operational } \\
\text { autonomy }\end{array}$ & $\begin{array}{l}\text { Attitude toward the } \\
\text { technological innovation }\end{array}$ & $0.119^{* * *}$ & $\begin{array}{l}\text { Personal } \\
\text { involvement }\end{array}$ & $0.369^{* * *}$ \\
\hline $\begin{array}{l}\text { CAS: } \\
\text { Environmental } \\
\text { sensitivity }\end{array}$ & $\begin{array}{l}\text { Attitude toward the } \\
\text { technological } \\
\text { innovation }\end{array}$ & $0.132^{* * *}$ & $\begin{array}{l}\text { Personal } \\
\text { involvement } \\
\text { Emotional } \\
\text { response }\end{array}$ & $0.368^{* * *}$ \\
\hline $\begin{array}{l}\text { CAS: Integration } \\
\text { of information }\end{array}$ & $\begin{array}{l}\text { Attitude toward the } \\
\text { technological innovation }\end{array}$ & $0.084^{* * *}$ & $\begin{array}{l}\text { Personal } \\
\text { involvement }\end{array}$ & $-0.203^{*}$ \\
\hline $\begin{array}{l}\text { CAS: Social } \\
\text { networking }\end{array}$ & $\begin{array}{l}\text { Attitude toward the } \\
\text { technological innovation }\end{array}$ & $0.055^{* * *}$ & $\begin{array}{l}\text { Personal } \\
\text { involvement }\end{array}$ & $0.317^{* * *}$ \\
\hline
\end{tabular}

Notes: $\mathrm{n}=300,{ }^{*} p<0.05 ;{ }^{* * *} p<0.001$

Hypothesis 1: A correlation between positive attitudes towards innovation and the Operational autonomy benefit that characterizes a knowledge worker in the organization as CAS: As shown in Table 2, this hypothesis was examined by means of a multivariate linear regression in which the predictive variables were the three dimensions of employee attitudes towards innovation: enthusiasm, influence, and involvement. It was found that the model comprising the three predictive variables is significant: $\mathrm{p}<0.001$ Adjusted $\mathrm{R}$ square $=0.119$. The main contribution was found to be a measure of "the degree of desire for involvement" -- beta $=0.369, \mathrm{p}<0.001$ 
Hypothesis 2: A correlation between positive attitudes towards innovation and the environmental / situational sensitivity of an employee in an organization characterized by CAS:

As shown in Table 2 the model containing the three predictive variables was found to be significant: $\mathrm{p}<0.001$ Adjusted $\mathrm{R}$ square $=0.132$. It was also found that the measure "the degree of desire for employee involvement in the process of assimilation of innovation" has a distinctly significant contribution to the prediction: beta $=0.368, \mathrm{p}<0.001$.

Hypothesis 3: A correlation between positive attitudes towards innovation and integration of information by the employee in the organization as CAS:

As shown in Table 2 the model containing the three predictive variables was found to be significant: $\mathrm{p}<0.001$ Adjusted $\mathrm{R}$ square $=0.084$. It was also found that the variable with a unique contribution to the prediction is the extent of the employee's desire to be involved in assimilating the innovation: beta $=0.317, \mathrm{p}<0.001$

Hypothesis 4: A correlation between positive attitudes towards innovation and the social networking of an employee in an organization characterized by CAS:

As shown in Table 2 the model containing the three predictive variables was found to be significant: $\mathrm{p}=0.001$ Adjusted $\mathrm{R}$ square $=0.055$. It was also found that the only variable that has a distinctly significant contribution is the extent of the employee's desire to be involved in assimilating the innovation: beta $=0.264, \mathrm{p}<0.001$

\section{Discussion}

The rapid pace of technological development influenced the need for a much faster rate of development of technological innovation in organizations, particularly those residing in a competitive environment (Arciénaga Morales et al, 2018). This need engenders an urge to assimilate innovation that can improve the organization's performance and enable it to reach fast, effective and valuable solutions for customers (Zhu, Kenneth and Xu, 2006).

Once the managers find innovative technologies tailored to the organization, they should implement a process of assimilating them within the organization. The process of assimilation of technological innovation in the organization may involve complex organizational changes. Hence, the need for technological innovation in an organization requires the processes of implementing innovation effectively and quickly (Bessen, Ford and Meurer, 2011).

The adaptive systems model [CAS] describes an organization that has a rapid adaptability to changes among employees who function as fractals within it (Shoham and Hasgall, 2005). These workers have a great deal of professional autonomy, social connections and constant integration of information (Hasgall; 2015). new research shows that functional autonomy of employees plays a significant role in workers' perceptions of pro-work behaviors, including taking initiative to find solutions and adapting work processes in the organization to environmental demands (Haas, Ryan and Hoebbel, 2018).

This study examined the relationship between the development of an employee's positive attitude toward processes of changes during an assimilation of technological innovation, and the variables 
that describe the employee's behavior in an organization with CAS characteristics. The assumption in this study is that an organization with CAS characteristics will allow the employee to become more involved in the process of assimilating technological innovation, and thereby develop positive attitudes towards the process of change (Bessen, Ford and Meurer, 2011). These positive attitudes have a great influence on the implementation of an efficient and faster process of assimilating innovation, in an era of great technological development and many changes in the market.

An analysis of the results of the study found that there was a significant positive effect of all four variables that represent the employee's behavior in an organization with CAS characteristics, the creation of positive attitudes and greater involvement of the employee in processes of technological change and innovation in the organization.

Another finding shows that there is a significant correlation between the employee's personal interest and the goals of the organization. The more the employee identified personal benefits from the innovative technologies and processes that are to be introduced into the organization, the more positive his/her attitude will be towards them. This is consistent with the "agreement" model, which claims that as employees agree with an implementation process, it will make it easier for the organization to make urgent changes, especially those that require the assimilation of technological innovation that is changing and renewing at a high rate.

It seems, therefore, that the positive attitudes towards changes due to assimilation of technological innovation in a CAS type organization have a direct and significant relationship to its perception of personal utility. However, do the organization's managers understand that there is a need to develop employees as knowledge workers and to design the work environment as a complex adaptive organization? Do they understand the need to strengthen the perception of the employee's personal benefits and positive attitude towards assimilating technological innovation in the organization?

In many cases, managers see the employee as part of the organization's resources and take for granted the cooperation with the assimilation process. They forget to check the personal and direct relationship of each employee to the innovation itself. This direct connection and the extent to which the employee will perceive the personal benefits from innovation will be among the main factors behind the development of positive attitudes towards innovation and thus the involvement and success of the innovation implementation process in the organization.

In view of this, it appears that employees working in an environment that allows them greater transparency and sensitivity, attending external conferences, participating in discussions and meetings, familiarity with competitors, exposure to technological innovation, understand the required process more, and keep the employees updated, will make them more positive and increase their level of involvement. The same is true of the variables: "integration of information" and "social networking". In both, there is a significant relationship and a significant impact on the development of positive attitudes of the employee to the process of assimilation of technological innovation in the organization.

The personal dimensions of this study should be noted. It turns out that the enthusiasm of the employees for the change stemming from the assimilation of technological innovation was moderate, but the degree of willingness to be involved was higher. It is reasonable to assume 


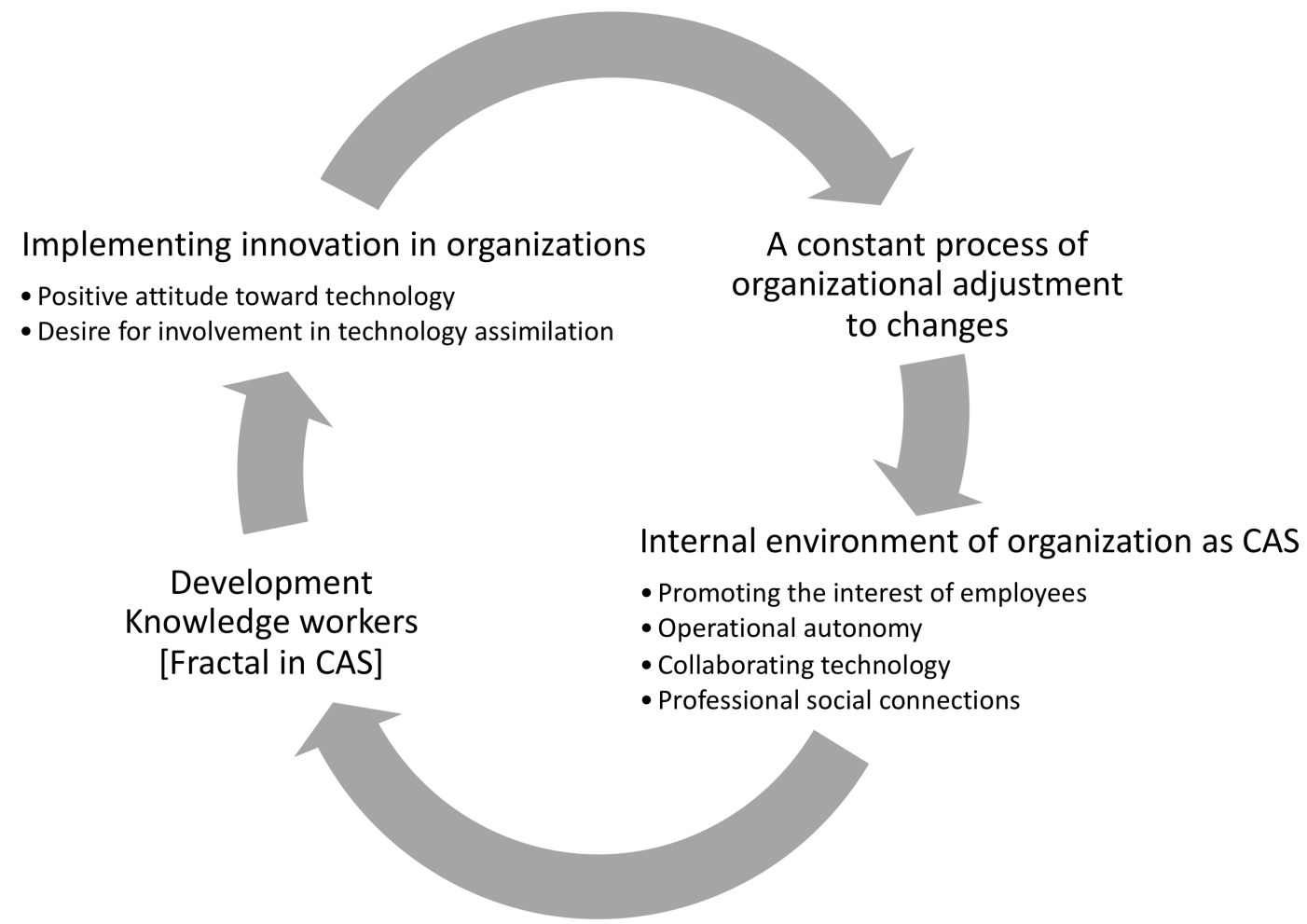

Fig. 3. A constant organizational process to adjust to innovation changes

that the greater is the degree of involvement of the employee in the process of assimilation, the greater is the enthusiasm for the innovative technology. This hypothesis should be examined in future research. Another important conclusion of this study is that the employee's individual perception of the organizational change generated by the innovation is critical to the success of the process. Apparently, the process of assimilating successful technological innovation requires constant and substantive involvement of the employees. It is important to allow employees to influence the implementation process, to be involved in the method, and to receive updates about times and locations for the implementation process. Equally important is the need to explain the benefits of innovation, and to allow employees to talk about and update the personal benefits they find in it. The major challenge for managers is to explain and even invest in marketing the benefits of innovation to employees within the organization. To allow employees to ask, to keep up to date, and to tell of cases in which innovation helped and upgraded their operations. The worker's involvement will not only advance the process of assimilation but will also adapt the technology to the work processes in the organization.

Ultimately, as shown on figure 3: an organization that that his internal environment will act like CAS, will encourage Knowledge workers, his Employee will start desire to involved will better cope with the assimilation process and achieve practical and effective adjustment to environmental complex demands and changes. 


\section{Practical contribution}

This study helps us to understand the great importance of the characteristics of the workspace within a CAS organization: the relationship between employees and managers, the ability to act autonomously and promote personal interests, the ability of the employee to manage the resources required for the work, the quality and friendliness of systems, the ability to update the activities, and to keep abreast of all the important things that are done in the organization. All these are the basis for the employees' ability to have a say in innovative processes and their implementation. Without the employee's ability to identify personal benefits, it will be difficult to implement the innovation, thus the organization will suffer from a delay in assimilation or from inferior competitive status.

It turns out that a working environment in an organization with complex adaptive system characteristics is an environment that is remarkably effective for the development of a knowledge worker who is capable of contributing and applying technological innovation in the organization in an optimal way. Such an employee will be able to cope better with changes, successfully assimilate technological innovation that comes from outside the organization, and perhaps even create technological innovation within the organization. This needs to be examined in further research.

If so, a working environment suitable for implementing innovation requires the organization to allow the employee operational autonomy. It is necessary to design a situation where the employee is granted responsibility and personal authority to reach a solution through the organization's resources and social networking. In this situation, the manager's roles change. From a manager of people who requires constant monitoring and control, to a process manager who tracks the progress of the process, enables resources and supports the employee's activity in this situation. The manager should let the employee to move toward a solution and do so through a process of innovation. In addition, there is a need for full transparency in the organization. This transparency will allow the employee to connect external customer requirements with the organization's objectives, organizational resources, and other employees at his side. This transparency should be pro-active. It should not only provide the employees with information, but also creates a situation of active updating of employees on the evolving changes and provide employees with technological platforms in order to update their knowledge and report about their activities. According to the findings of this study, systems that support social networking are preferable. The organization must recruit employees with autonomous work ability and technological readiness to use information systems and social networking. When the employee enters the organization, he/she must be given comprehensive training regarding the use of these information systems for the purpose of updating, transparency, and cooperation. The employee's ability to be up-todate and involved in the organization's work processes will generate positive attitudes towards innovation and will actively participate in intra-organizational innovation.

Another recommendation is the role of the CDO (Chief Digital Officer). The organizational innovation manager, who knows the work methods required to create innovation, understands the conditions required, knows the sources of innovation, and adapts them to the requirements of the organization, its goals, and business model. 


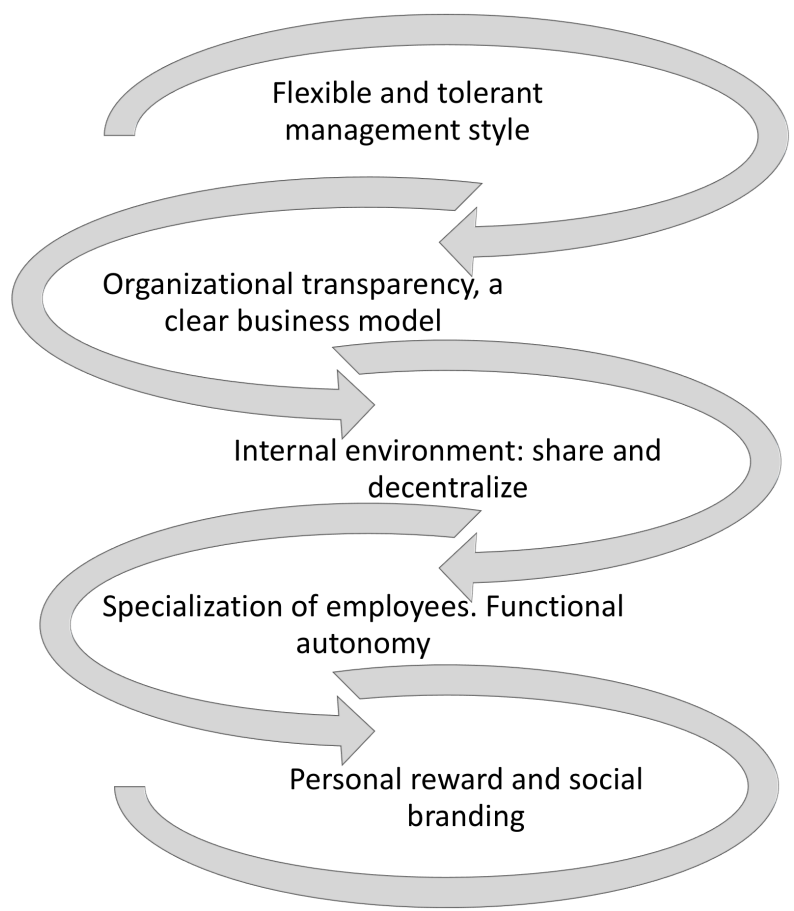

Fig. 4. A process of Innovative response in CAS organization

Transformation from a traditional organization to an organization with CAS characteristics

As found, in an environment characterized as CAS, the potential to assimilate innovation as required can significantly improve. If so, what is the proper way to transform the internal organization form into that of a CAS?

As shown in Figure 4. The Internal organizational environment As CAS affects the organizational ability to response innovatively to changing requirements.

So, before the transition of the internal organizational environment to be characterized as a CAS, there is a need to change the management concept to one that will not place too much emphasis on excessive and intrusive control by managers. On the contrary, the new managerial style should encourage managers to enable knowledge workers to experiment, to cope, to make independent decisions, and to develop their own innovative solutions. They should not be "punished" for trying to peruse ideas that eventually fail. In lieu, they should be praised for trying to think out of the box. In such internal organizational environment, each worker has to be considered as an autonomous fractal capable of applying his/her own solution in his/her own time. Managers need to reflect to employees the business model required, the organizational goals and the main challenges and tasks facing the organization. The internal environment has to contain procedures enabling the worker to obtain the information and resources needed for developing required solutions in time, without having to be subject to the on-going managerial control. As part of the development of a management concept that will enable the knowledge worker to act optimally, it is necessary to deploy organizational transparency. The worker has to "feel" the demands arising from the external organization's environment and respond immediately to innovative solutions 
and to the cooperation of the other fractals in the environment. An organization that is interested in the development of a knowledge worker must also allow him/her to experience processes outside the organization, and to keep up with any new findings relevant to his work.

Organizational transparency is reflected in a continuous and up-to-date flow of top-down information on the organization's activities vis-a-vis customers and competitors. Information on business models used in the organization, on new requirements arising from the customers of the organization, on new technologies introduced into the organization, on the types of products and services provided by the organization, should be circulated continuously. Most of the information mentioned above is now confined to senior executives in the organization. However, today, the organization's environment is dynamic, complex, and stormy. The organization relies on the ability of the knowledge workers to develop and innovate solutions adapted to changing requirements. Therefore, an internal organizational environment characterized by CAS, which enables the development of knowledge workers, must be transparent, using open access techniques that enable the worker to operate autonomously and develop solutions according to immediate requirements. The knowledge worker will not be able to do so without familiarity with and understanding of the core of the organizational activities. In an organization with CAS-like characteristics, managers have to focus on the quality of the work processes, the transfer of resources, and the support to knowledge workers' activities, rather than the supervision and control of each employee's daily activities. Manager can take the responsibility to transfer relevant knowledge from one worker to another rather than to monitor and re-monitor the status of each task.

Another element in the internal organizational environment focuses on the combination of the transfer of innovative solutions and the operational autonomy. Yet, the usual internal organizational environment does not allow the employee to stand out. In an organization with CAS-like characteristics, it is necessary to change this perception. The internal environment characterized in a CAS, must allocate each fractal knowledge worker, to develop in the organizational ecosystem, and to promote personal interests of working groups focused on specific solutions or developing knowledge on core organizational issues.

Workers must be allowed to relate to their innovative solutions not only as part of achieving organizational goals, but also as part of promoting their professional and social personal interest. The knowledge worker should be exposed to social and professional recognition and be able to become a "unique brand" among the managers and co-workers. This recognition is a key tool in maintaining an employee's ability to function as a knowledge worker. Management should create an atmosphere that directly and independently rewards each employee in line with his/her contribution to the organizational knowledge, and to the integration with other employees. From this point onwards, it is easy to implement a systematic process of developing and disseminating innovation in the organization with the participation of every employee and adapting it to events, tasks, changes, and external requirements. The innovation is shared independently and immediately by each employee (Hasgall,2015). Social communication technologies tools are also required elements in an internal organizational environment as CAS. The social communication technologies tools include knowledge systems, social networks, social and group communication applications, whose function is not only to convey information and to enable the workers to update their knowledge on a regular basis, but also to support ongoing social networking. This social integration provides the worker with emotional support and the ability to receive credit 
and recognition from colleagues and managers immediately and continuously. Such recognition encourages personal development as part of the improvement of abilities and social status

\section{Avenues for further research}

This study focused on understanding the relationship between positive attitudes and perceptions of employees towards the process of assimilating innovation in the organization as an adaptive complex system (CAS). This study examined the relationship between each of the variables. Future studies can further develop the findings by examining the cumulative effects of the variables examined here. In addition, it should be noted that the study was conducted in one country only. However, this country is well advanced in the areas of innovation and therefore it can be assumed that the sample can also represent populations in other developed countries. It seems that the sample size is large enough to draw conclusions, and the findings presented here seem reliable - at least as a basis for broader, multinational research.

\section{References}

Akgün, A. E., Keskin, H., Byrne, J. C., \& Ilhan, Ö. Ö. (2014). Complex adaptive system mechanisms, adaptive management practices, and firm product innovativeness. REDD Management, $44(1), 18-41$.

Andriani, P., \& Cattani, G. (2016). Exaptation as source of creativity, innovation, and diversity: Introduction to the special section. Industrial and Corporate Change, 25(1), 115-131.

Anjariny, A. H., Zeki, A. M., \& Hussin, H. (2012, November). Assessing organizations readiness toward business intelligence systems: a proposed hypothesized model. In 2012 International Conference on Advanced Computer Science Applications and Technologies (ACSAT) (pp. 213218). IEEE.

Armstrong, C. P., \& Sambamurthy, V. (1999). Information technology assimilation in firms: The influence of senior leadership and IT infrastructures. Information systems research, 10(4), 304-327.

Bessen, J., Ford, J., \& Meurer, M. J. (2011). The private and social costs of patent trolls. Regulation, 34, 26.

Camisón, C., \& Villar-López, A. (2014). Organizational innovation as an enabler of technological innovation capabilities and firm performance. Journal of business research, 67(1), 28912902.

Christensen, C. M., Bartman, T., \& Van Bever, D. (2016). The hard truth about business model innovation. MIT Sloan Management Review, 58(1), 31.

Crossan, M. M., \& Apaydin, M. (2010). A multi-dimensional framework of organizational innovation: A systematic review of the literature. Journal of management studies, 47(6), 11541191. 
Denning, P. J., \& Dunham, R. (2010). The innovator's way: Essential practices for successful innovation. MIT Press.

Freeman, C., \& Soete, L. (2009). Developing science, technology and innovation indicators: What we can learn from the past. Research policy, 38(4), 583-589.

Garud, R., Tuertscher, P., \& Van de Ven, A. H. (2013). Perspectives on innovation processes. Academy of Management Annals, 7(1), 775-819.

Hasgall, E. A. (2015), From assimilation to acclimatization of social digital Technology in organizations. International Journal of Computer Systems (IJCS). 2: (10).

Hasgal, A., \& Ahituv, N. (2017, December). The Development of Knowledge Workers in an Organization characterized as Complex Adaptive Systems (CAS). In International Conference on Intellectual Capital and Knowledge Management and Organisational Learning (pp. 97-103). Academic Conferences International Limited.

Haas, E., Ryan, M., \& Hoebbel, C. (2018). Job Autonomy and Safety Climate: Examining Associations in the Mining Industry. Professional Safety, 63(12), 30-34.

Hasgall, A. E., \& Shoham, S. (2015). Effective use of digital applications promotes professional self-efficacy. Vine, 45(2), 279-291.

Holland, J. H. (2006). Studying complex adaptive systems. Journal of systems science and complexity, 19(1), 1-8.

Jackson, M. O. (2010). Social and economic networks. Princeton university press.

Jackson, D. J. (2011). What is an innovation ecosystem? National Science Foundation, 1. Accessed April 2019: http://erc-assoc.org/content/what-innovation-ecosystem.

Lundvall, B. A. (Ed.). (2010). National systems of innovation: Toward a theory of innovation and interactive learning (Vol. 2). Anthem press.

Arciénaga Morales, A., Nielsen, J., Bacarini, H., Martinelli, S., Kofuji, S., \& García Díaz, J. (2018). Technology and innovation management in higher education - Cases from Latin America and Europe. Administrative Sciences, 8(2), 11.

Potter, K., \& McGittigan, G. (2013). IT Metrics: A Critical Evaluation of Decentralized IT Spending and Digital Enterprise Readiness. Gartner, Inc.

Oliveira, T., \& Martins, M. F. (2011). Literature review of information technology adoption models at firm level. Electronic Journal of Information Systems Evaluation, 14(1), 110.

Oreg, S. (2003). Resistance to change: Developing an individual differences measure. Journal of applied psychology, 88(4), 680.

Roos, J., \& Oliver, D. A. V. I. D. (1997, February). The poised organization: Navigating effectively on knowledge landscapes. In LSE complexity and strategy seminar.

Snihur, Y., \& Tarzijan, J. (2018). Managing complexity in a multi-business-model organization. Long Range Planning, 51(1), 50-63. 
Shoham, S., \& Hasgall, A. (2005). Knowledge workers as fractals in a complex adaptive organization. Knowledge and Process Management, 12(3), 225-236.

Stacey, R.D., Griffin, D. and Shaw, P. (2000). Complexity and management: Fad or radical challenge to systems thinking? London: Rutledge.

Snihur, Y., \& Tarzijan, J. (2018). Managing complexity in a multi-business-model organization. Long Range Planning, 51(1), 50-63.

Schumpeter, J. A. (1991). The economics and sociology of capitalism. Princeton University Press.

Törnberg, P. (2014). Innovation in Complex Adaptive Systems. Thesis for the degree of Licentiate of Engineering. Chalmers University of Technology.

Accessed April 2019: http://publications.lib.chalmers.se/records/fulltext/203938/203938.pdf

Zimmerman, B. J., \& Hurst, D. K. (1993). Breaking the boundaries: The fractal organization. Journal of Management Inquiry, 2(4), 334-355.

Zhu, K., Kraemer, K. L., \& Xu, S. (2006). The process of innovation assimilation by firms in different countries: a technology diffusion perspective on e-business. Management science, 52(10), $1557-1576$. 


\section{Biographies}

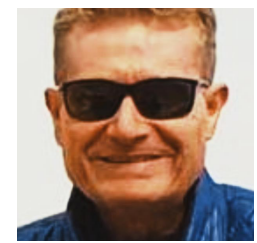

Alon E. Hasgall. Today, he is a faculty member in the Department of Business Administration at the Center for Academic Studies, Or Yehuda, Israel. Researcher, senior lecturer and program director. Head of the Center for Innovation in the Information Technology Bureau, a board member of international academic journals. In the past, Alon was in the Israel Defense Forces until 1998 and is a lieutenant colonel in the reserves. He received his doctorate from Bar-Ilan University, Israel in 2004. He then worked on assimilating innovative technologies as a project manager in high-tech companies, and later founded and managed social technology start-ups. Between 2010-2010 he served as the Director and Chairman of the Israel Internet Association. Alon's range of occupations has enabled him to develop as an expert consultant to companies and organizations in the fields of digital transformation and the assimilation of smart technological innovation in organizations.

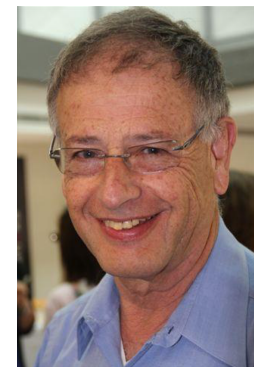

Niv Ahituv. A Professor Emeritus of Tel Aviv University. He was the founder (2003) and the Academic Director of the Institute of Internet Studies and held the chair for Research in Information Evaluation at Tel Aviv University. From 1989 to 1994 he served as the Dean of Graduate School of Business Administration, and from 1999 to 2002 he served as Vice President and Director General (CEO) of Tel Aviv University. Since 2006 he represents the Israeli Academy of Sciences in CODATA - an international committee on Data Sciences, where he was a Vice President from 2014 to 2018. He holds degrees of B.Sc. in Mathematics, MBA, M.Sc. and Ph.D. in Information Systems Management.

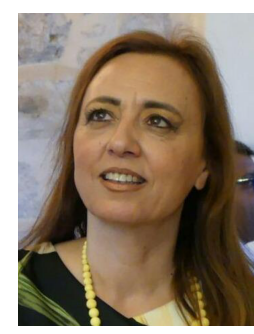

Nily Naveh. Dr. Nili Naveh began her technological career in the I.D.F and was part of the development teams for applications in advanced technological fields, starting from the perspective of development and the integration of advanced systems into existing systems. Her last job was head of project which develop simulation systems. Upon completion of her position in I.D.F. She takes part into the business world. She has been engaged in technology, innovation and solutions for clients and organizations for nearly 40 years. Her Technological knowledge gives her ability to identifying innovation and addressing the relevance of the organization as a key player in the market. In addition to her work in the business market, she is involved in technological education in Israel. She has written and authored curricula, lectured at colleges and academia for many years, and takes part in the implementation of innovative software programs in Israeli schools. For ten years she worked in the field of technological education networks in Israel, both in leading technological schools, integrating the industry in education, introducing innovation into the learning system and developing projects by students. In her last position she served as VP of pedagogy and technology in a national educational network - the second largest in Israel. Dr. Nili Naveh's heterogeneity of work - a combination of education and a business market - is characterized by the constant search for innovative technology and the ability to identify new technology relevant to the organization, with the goal of advancing it to achieve its objectives. The expertise of Dr. Nili Naveh is expressed in the business development of organizations, while adapting innovation to the nature of the organization and its activities.

ISSN 2183-0606

http://www.open-jim.org

http://creativecommons.org/licenses/by/3.0 